\title{
Predicting Academic Success of Health Science Students for First Year Anatomy and Physiology
}

\author{
Ryan S Anderton ${ }^{1,2}$, Tess Evans ${ }^{1} \&$ Paola T Chivers ${ }^{2}$ \\ ${ }^{1}$ School of Health Sciences, University of Notre Dame Australia, Fremantle, Western Australia \\ ${ }^{2}$ Institute for Health Research, University of Notre Dame Australia, Fremantle, Western Australia \\ Correspondence: Ryan S Anderton, School of Health Sciences, University of Notre Dame Australia, Fremantle, \\ Western Australia; Institute for Health Research, University of Notre Dame Australia, Fremantle, Western Australia
}

Received: December 16, 2015

Accepted: January 5, 2016

Online Published: January 12, 2016

doi:10.5430/ijhe.v5n1p250

URL: http://dx.doi.org/10.5430/ijhe.v5n1p250

\begin{abstract}
Students commencing tertiary education enter through a number of traditional and alternative academic pathways. As a result, tertiary institutions encounter a broad range of students, varying in demographic, previous education, characteristics and academic achievement. In recent years, the relatively constant increase in tertiary applications in Australia has not translated to an increase in student retention or graduate numbers. The Health Sciences discipline typically falls within this paradigm, prompting various approaches to promote academic success and overall student retention. In this study, the demographic and previous education of health science students at an Australian University, were analysed along with first year science grades from a core first year anatomy and physiology unit. A generalized linear model (GLM) demonstrated statistically significant relationships between performance in the unit (measured by grade point average) and year 12 Australian Tertiary Admissions Rank (ATAR) subjects (human biology and chemistry; $p<0.001)$ and gender $(p<0.001)$. No significant performance correlation was observed with household socioeconomic status, as measured by socio-economic indexes for areas. Taken together, the results from this study facilitate estimation of academic success by some parameters prior to their commencement at University.
\end{abstract}

Keywords: Anatomy, Prediction, Academic performance, Australian

\section{Introduction}

Predictors of academic success or failure in the tertiary environment are pivotal in shaping curricula and support services. Students entering Australian universities particularly struggle in science, engineering and mathematic degrees (Hassan, 2008). Academic staff have found it challenging to address this issue, which is amplified by the diversity of students entering the university system. In particular, entrance via alternative pathways into Australian Universities has been enhanced (Macey, Jordan, Jackson, \& Money, 2006), resulting in significant breadth in the academic abilities and prior knowledge of first year students. Identifying fixed and apparent predictors of academic performance among transitioning students is needed to tailor support to those at risk of underperforming and potentially improve student retention and ultimately graduation.

Demographic markers such as age (Sheard, 2009), socioeconomic status (Li \& Dockery, 2014), gender (Sheard, 2009), high school performance (Hoffman \& Lowitzki, 2005; Richardson, Abraham, \& Bond, 2012) and employment (Stinebrickner \& Stinebrickner, 2003) have previously been investigated as predictors for academic performance across a range of university degrees. Studies on the effect of age have been inconsistent, with both positive and negative reported correlations for academic success (Naderi, Abdullah, Aizan, Sharir, \& Kumar, 2009; Sheard, 2009). However, an Australian study using input-output analysis found that a 20 year old undergraduate student has the highest probability of completing a course, and that the age of commencement is a strong indicator (Shah \& Burke, 1996). These inconsistencies may relate to variations across degree, university and country; indeed this is the case for gender analyses (Harackiewicz, Barron, Tauer, \& Elliot, 2002). A study of Australian university students observed no performance difference between males and females in science (McKenzie \& Schweitzer, 2001) or graduate entry medicine (Puddey \& Mercer, 2014). However, females performed considerably better in the majority of subject fields at Australian high schools (Fischer, Schult, \& Hell, 2013). Gender disparate predictors of success identified in our analysis may shed light on these discrepancies. 
The school of health sciences at this University offers undergraduate degrees in biomedical science (BMS), exercise and sports science (BESS), health and physical education (HPE), and other broad health-related degrees. A traditional entry pathway into one of these degrees involves the successful completion of year 12 and a requisite Australian Tertiary Admission Rank (ATAR) score, comprising of four or more stage 2/3 subjects. While students can enter these degrees with any combination of secondary subjects, competency in English is a prerequisite. While the majority of students enter into university study through a traditional secondary education pathway, there are several alternative university entrance pathways available to mature-age students. The addition of those entering via previous tertiary study, foundation year or technical and further education (TAFE) preliminary qualifications creates a heterogeneous pool of students with concomitant disparities of prior knowledge, learning pace, and digital literacy.

This study aims to investigate predictors of performance using three first year cohorts of health science students studying first year anatomy and physiology. We sought first to demonstrate that a core Anatomy and Physiology unit (Human Structure and Function; BMS100) score was representative of first year GPA. From this point, the study sought to ascertain whether there is a difference in the ability of first year students from BESS, HPE, and BMS degrees to successfully complete the BMS100 unit. Further we explore whether specific demographic factors would predict performance. The ability to identify subsets of students who transition poorly to health science degrees at university would provide better targeted student support aimed to improve student performance, satisfaction, retention and ultimately graduation.

\section{Methods}

\subsection{Participants}

First year students from three different health science degrees at this University were included in this study across intake years 2012 - 2014. The total student sample $(n=414)$ comprised three BMS100 semester cohorts spanning $2012(n=127), 2013(n=112)$ and $2014(n=175)$. The male to female ratio within the sample changed from 2012-2014, with female proportion progressively increasing by $10 \%$ (Table 1). Similarly, the ratio of school leavers to non-school leavers (alternative entry and mature age) enrolments shifted to favour school leaver enrolments by $10 \%$ in the same period (Table 1). School leavers were defined as students less than 20 years of age who gained entry to their Health Sciences degree employing a valid ATAR score (within two years). Mature age and/or alternative entry students were over the age of 18 years and gained entry by foundation year, tertiary enabling program, TAFE certification or previous tertiary semesters.

Table 1. Composition of BMS100 students by gender and mode of tertiary entrance

\begin{tabular}{cccc}
\hline Academic Year & $\mathbf{2 0 1 2}$ & $\mathbf{2 0 1 3}$ & $\mathbf{2 0 1 4}$ \\
\hline Male & $54.4 \%$ & $49.2 \%$ & $44.5 \%$ \\
Female & $45.6 \%$ & $50.8 \%$ & $55.5 \%$ \\
Total & $100.0 \%$ & $100.0 \%$ & $100.0 \%$ \\
School Leaver & $52.8 \%$ & $59.8 \%$ & $62.8 \%$ \\
Mature Age & $47.2 \%$ & $40.2 \%$ & $37.2 \%$ \\
Total & $100.0 \%$ & $100.0 \%$ & $100.0 \%$ \\
\hline
\end{tabular}

\subsection{Academic Performance Measures}

Student's pre- university entrance performance measures included ATAR score, stage 3 year 12 high school subjects and mode of university entrance, which is divided into two pathways; direct school leavers (based on ATAR score) and non-direct school leaver (alternative and mature age) students. Both alternative entry and mature age students qualify on the basis of previous tertiary semester, TAFE certification or advanced standing, and/or completion of foundation year or tertiary enabling programs. Given the heterogeneous education background of these cohorts, a preliminary literacy assessment undertaken by students was also included to estimate its role in first year performance.

Academic performance in the core first year anatomy and physiology unit, Human Structure and Function (BMS100), was assessed as a specific marker for success in health science. The anatomy and physiology unit consists of a mid-semester exam (weighted 15\%), online and laboratory assessments (15\%), practical exam (weighted 20\%) and final exam (weighted 50\%). In addition, following the completion of first year, grade point averages (GPA) for full-time students were calculated as a general measure for first year performance. For GPA 
calculations, student unit results were awarded a 0 (Fail, <50), 1 (Pass, 50-59), 2 (Credit, 60-69), 3 (Distinction, 70-79) or 4 (High Distinction, 80-100).

\subsection{Assessment of Socioeconomic Status}

Socioeconomic status (SES) was indirectly measured from socioeconomic indexes for areas (SEIFA). The listed residential postcode of students were categorised according to the 2011 Australian Bureau of Statistics' socio-economic indexes for areas (ABS, 2013). Postcodes were assigned a value of 1-10 corresponding to the Western Australian SES percentile for that postcode. For example, high SES suburbs were in the top percentile bracket (90-100) and were awarded a value of 1, with the lowest percentile bracket (1-10) awarded a value of 10.

\subsection{Literacy Assessments: Reading and Writing Ability}

The internal post-entrance literacy assessment (PELA) was used to determine the writing and reading abilities of students in this study. This test is delivered to all students who are commencing health science degrees at an Australian University. Briefly, the test involves a reading and comprehension section, a vocabulary test, and a final section requiring the production of an extended piece of writing. For reading, each student receives a score (1-10). This score was also converted to a tertile (low, medium and high). Writing ability was assessed by the university's Academic Enabling and Support Centre (AESC) through a structured extended piece of writing, and recorded as "sufficient" or "not sufficient."

\subsection{Data Analysis and Ethics}

Data were described and analysis was conducted using SPSS version 22 (IBM corporation). Group differences in academic performance were analysed using an independent t-test or one-way ANOVA with a $p$ value of <.05 threshold considered statistically significant. A general linear model (GLM) was used to analyse the relationship between the pre-entry factors and student grade in the core first year anatomy and physiology unit from 2012-2014. The pre-entry variables used in the GLM included gender, SES, degree, literacy and high school ATAR level human biology, biology, chemistry, physics and mathematics. Non-significant factors were removed one at a time until the final model was determined. Ethical approval to obtain student demographic data, including previous high school subjects, was granted by the University’s Human Research and Ethics Committee.

\section{Results}

\subsection{Percentage Score in BMS100, A First Year Anatomy and Physiology Unit, is Representative of First Year GPA}

A lasting belief in health sciences, based on anecdotal evidence, is that performance in anatomy and physiology typifies overall degree performance. We first sought to verify this in our sample, which comprised three cohorts (2012-2014) of a core anatomy and physiology unit (BMS100). Student final percentage score in BMS100 and their mean first year GPA were found to be highly concurrent (Figure 1). A student's grade in BMS100 and their first year GPA have a statistically significant $(p<.001)$ positive linear relationship in $2012(r=.75), 2013(r=.82)$ and $2014(r$ $=.85)$. Most notably, in all three cohorts, students receiving a high distinction in BMS100 averaged a GPA greater than 3.00 (0-4 scale). Reciprocally, students who receive a pass or fail grade, average a GPA of less than 1.3 and 1.1 respectively at the completion of first year (Table 2).

Table 2. First year performance in health science (BMS100) and Mean (SD) GPA scores across years 2012-2014

\begin{tabular}{cccc}
\hline Academic Year & $\mathbf{2 0 1 2}$ & $\mathbf{2 0 1 3}$ & $\mathbf{2 0 1 4}$ \\
\hline BMS100 Grade & $\mathbf{1}^{\text {ST }}$ Year GPA Mean (SD) & $\mathbf{1}^{\text {ST }}$ Year GPA Mean (SD) & $\mathbf{1}^{\text {ST }}$ Year GPA Mean (SD) \\
HD & $3.16(.69)$ & $3.03(.41)$ & $3.37(.41)$ \\
D & $2.37(.45)$ & $2.26(.46)$ & $2.21(.41)$ \\
C & $1.79(.46)$ & $1.73(.42)$ & $1.65(.32)$ \\
P & $1.27(.46)$ & $1.10(.36)$ & $1.26(.43)$ \\
F & $1.04(.45)$ & $1.10(.33)$ & $0.99(.31)$
\end{tabular}




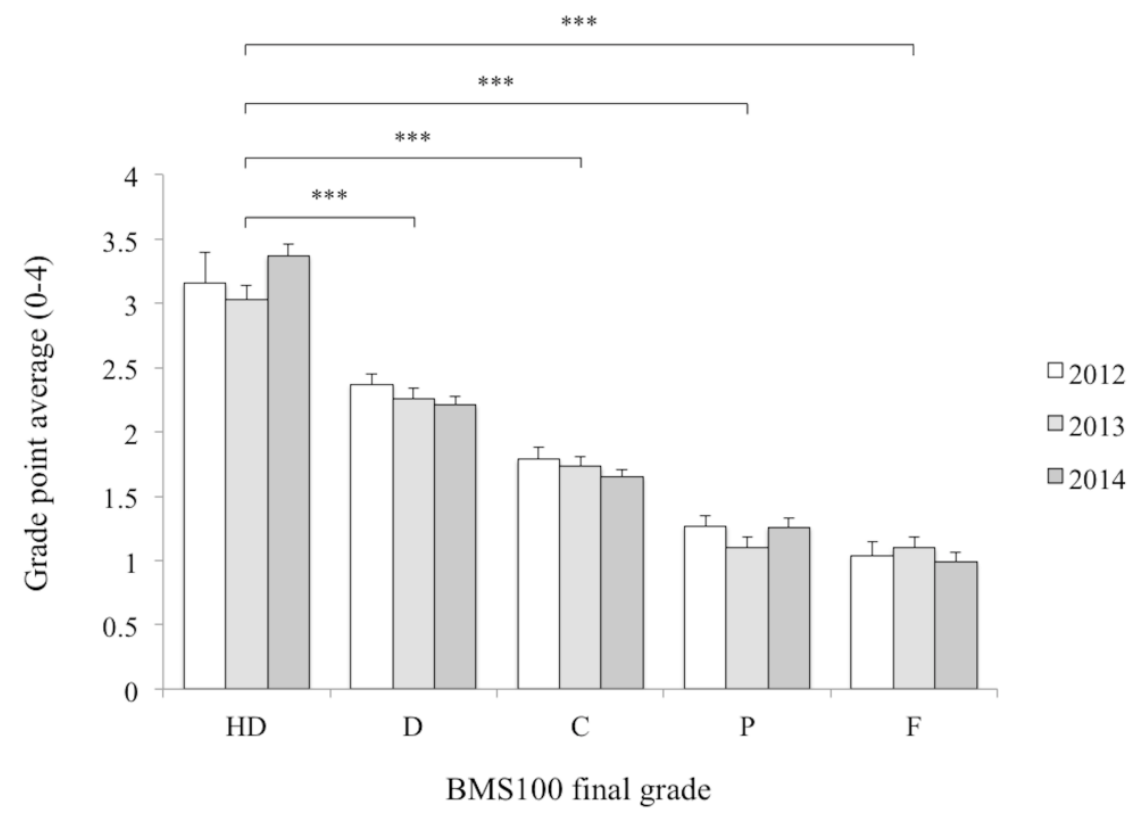

Figure 1. A student's grade in a core first year anatomy and physiology unit, BMS100, correlates to academic success in the first year of their health science degree. Student grades ranging from a high distinction (80-100), distinction (70-79), credit (60-69), pass (50-59) and fail $(<50)$ correlate with the grade point averages $(0-4)$ of full time health science students following the completion of first year $(* * *<<0.001)$.

\subsection{Demographic Predictors Influencing Success in First Year Anatomy and Physiology}

Having demonstrated that the BMS100 unit is a satisfactory representation of overall performance in first year health science, we next set out to determine which factors influenced our cohort's performance. Student demographic data was examined as a possible influence on BMS100 performance (Figure 2). Within the health science degree program, females performed better (2.8-7.8\%) than males across years, but were only statistically significant in 2012 and 2014 (2012: $t=2.88, p=.005 ; 2014: t=2.85, p=.005$ ). Interestingly, student socioeconomic status was not associated with higher academic performance in any of the three cohorts (Figure 2b). Students who entered university via their ATAR had higher BMS100 performance scores across all three cohorts (3.7-7.8\%) (2013: $t=$ $3.46, p=.001 ; 2014: t=2.27, p=.024)$. Due to the University recording process, data was unavailable to delineate the effect of entry pathway subsets of alternative entry and mature age students. 
A.

$\underline{\text { Gender }}$

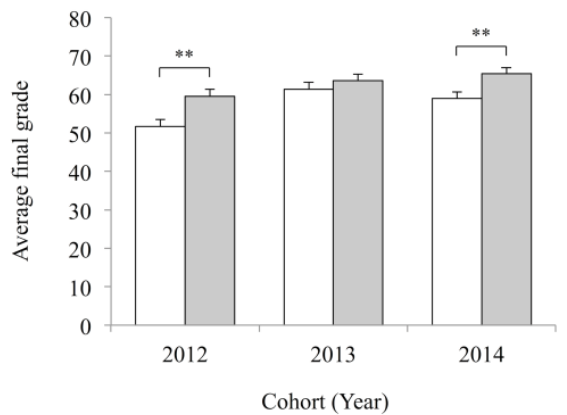

C.

$\underline{\text { ATAR entry }}$

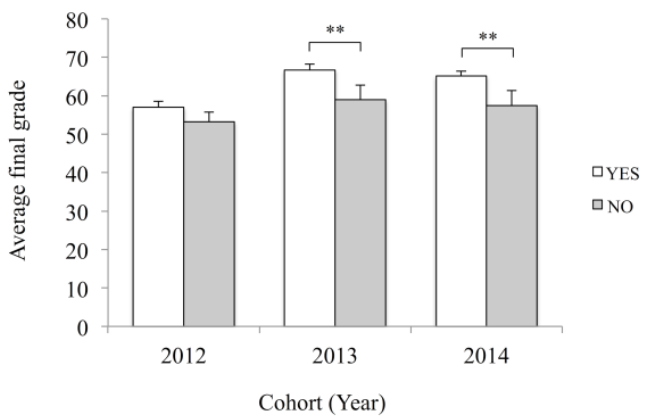

B.

\section{Suburb SES}

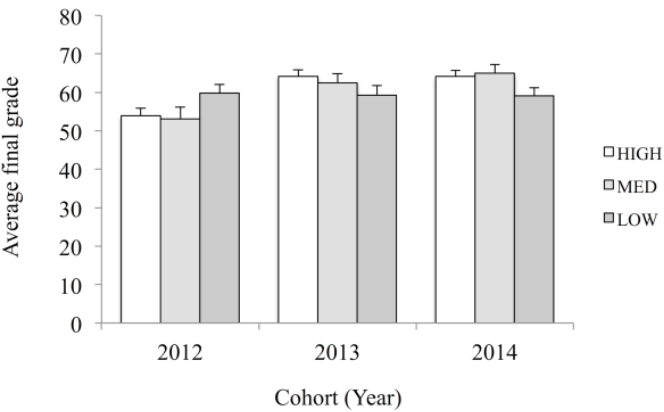

D.

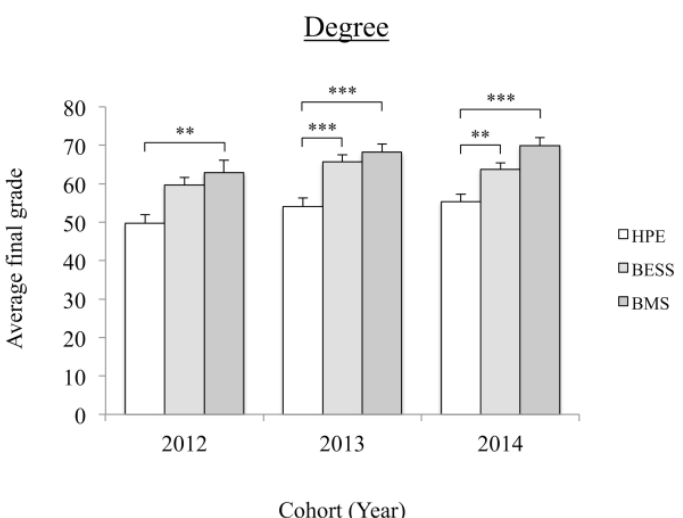

Figure 2. Demographic predictors and choice of degree effect student performance in first year anatomy and physiology. (A) The effect of student gender, (B) socioeconomic status, (C) university admission pathway, and (D) health science degree on BMS100 final grade $(* p<.05 ; * * p<.01 ; * * *<<.001)$.

Using a one-way ANOVA, degree program showed a significant difference between BMS and HPE students in BMS100 performance in $2012(F=5.49, p=.004), 2013(F=12.85, p<.001)$ and $2014(F=12.15, p<.001)$ year groups, with the former performing 13.1-14.5\% better. Similarly, BESS students were significantly better performers in BMS100 in $2013(F=12.85, p<.001)$ and $2014(F=12.15, p=.003)$ when compared with students in the HPE degree (Figure 2d).

\subsection{Assessment of Literacy as a Predictor for Success in First Year Anatomy and Physiology}

Upon admission, students in health sciences take the post-entrance literacy assessment (PELA). Health science students who were deemed "sufficient" in writing tasks performed significantly better in $2012(t=2.82 ; p=.006)$ $2013(t=2.41, p=.017)$ and $2014(t=2.08, p=.039)$ than those requiring improvement (Figure 3). Strong performance on the reading portion of the PELA test showed a trend to higher performance in BMS100 across all three years. While not significant, we observed a difference in mean BMS100 grade of between 4-6\% from high to low reading score tertiles (see figure 3 ). 
A.

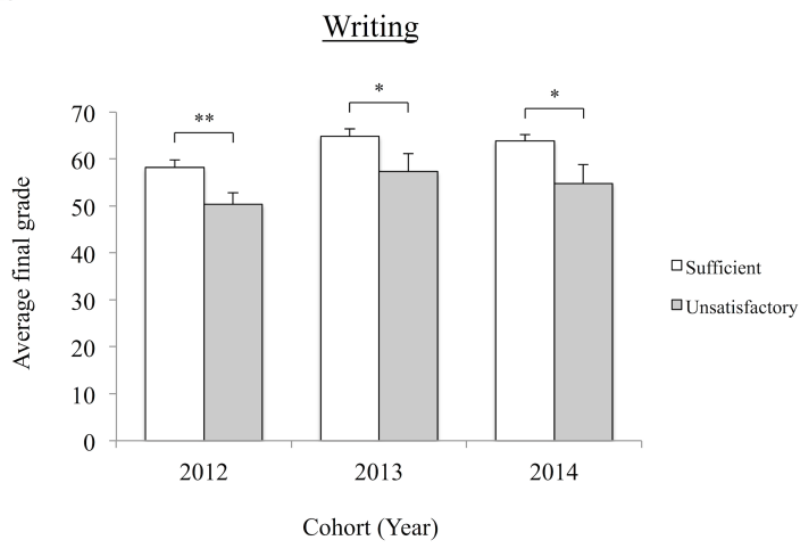

B.

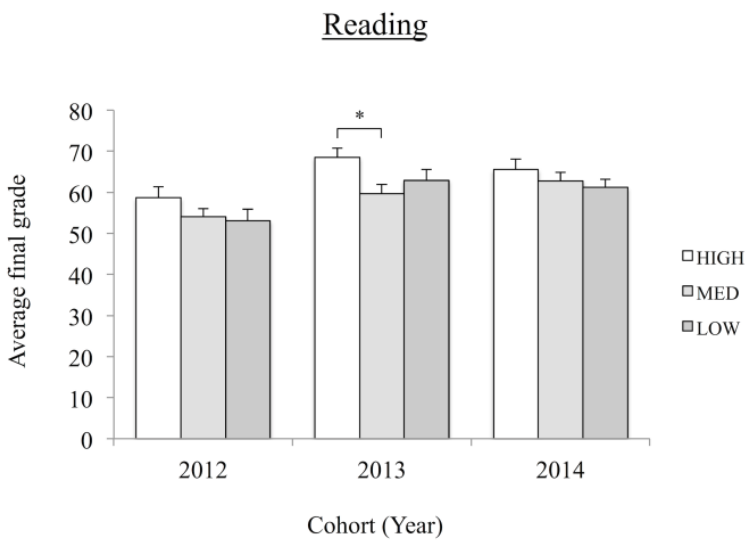

Figure 3. Literacy assessments as a predictor for student performance in first year anatomy and physiology. The effect of (A) student writing competency, and (B) reading competency on BMS100 grades, as determined by the post-entrance literacy assessment $(* p<.05 ; * * p<.01)$.

3.4 Previous Science and Mathematics Exposure can Influence Student Grades in A First Year Anatomy and Physiology Unit

Differences between previous study and academic success in first year anatomy and physiology, secondary school subjects and previous tertiary degrees were compared to final BMS100 grades using independent $t$ tests (Figure 4). Previous completion of ATAR human biology was associated with higher BMS100 grades by between 7-9\% in 2012 $(t=2.52, p=.013), 2013(t=2.62, p=.01)$ and $2014(t=4.32, p<.001)$ (Figure 4a). Similarly, completion of ATAR chemistry prior to University was associated with higher BMS100 performance scores in all cohorts (2012: $t=4.09$, $p<.001 ; 2013: t=3.51, p=.001 ; 2014: t=4.43, p<.001$ ) (Figure 4d). While prior completion of ATAR physics was associated with a higher BMS100 performance score, this was only statistically significant in $2012(t=2.90, p$ $=.004)$ and $2014(\mathrm{t}=3.45, p=.001)$ (Figure 4c). It should be noted that only a small number of students $(\mathrm{n}<25)$ studied ATAR physics in each cohort year. Finally, higher-level ATAR mathematics (Western Australian 3AB/3CD) was associated with higher BMS100 grades between 5-9\%, in $2012(\mathrm{t}=2.47, p=.015), 2013(\mathrm{t}=2.25, p=.027)$ and $2014(\mathrm{t}=4.18, p<.001)$ (Figure 4). Students who previously studied biology or physical education (PE) studies did not perform any better in BMS100 than students with no prior exposure (Figure 4).

\subsection{A Combination of Factors can Predict Academic Success in First Year Anatomy and Physiology}

To identify what combination of factors might be associated with academic success in BMS100, multiple factors were assessed in combination. To determine if general exposure to ATAR level science (human biology, chemistry or physics) during high school sufficiently prepared and enhanced student performance in first year, independent $t$ tests were used for each year cohort. Previous study in one or more science subjects at a year 12 standard (previous science) was associated with a significantly higher academic performance by $10-16 \%$ in all three cohorts $(p<.001)$ of studying BMS100 compared to no previous science (Figure 5a). Higher BMS100 grades occurred when combining previous study of chemistry with the writing portion of the PELA literacy assessment (Figure 5). Students in all three cohorts showed a significantly higher score $(p<.001)$ of between 12-18\% in BMS100 grade following completion of ATAR chemistry and writing proficiency (Figure 5B). 
A.

Human Biology

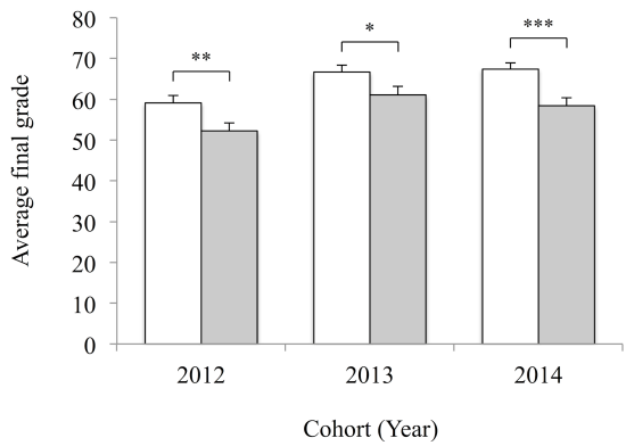

C.

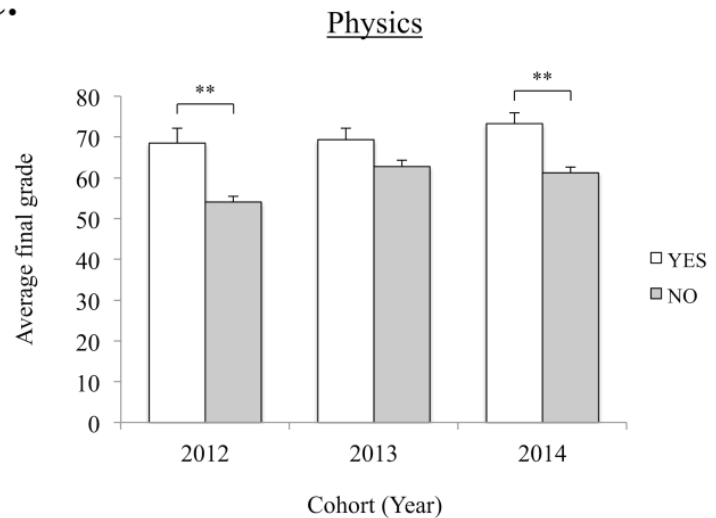

E.

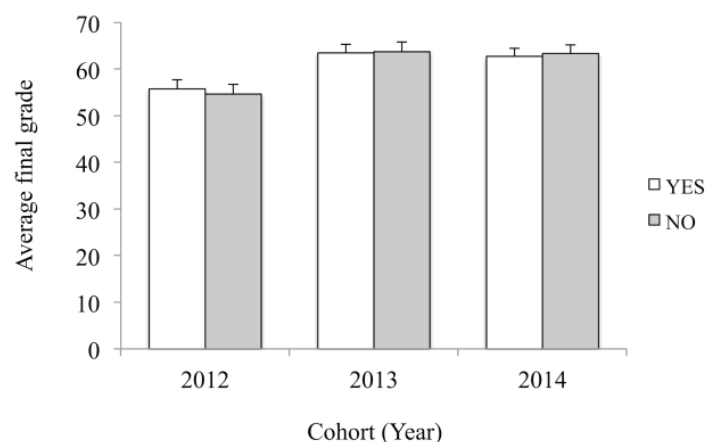

B.

Biology

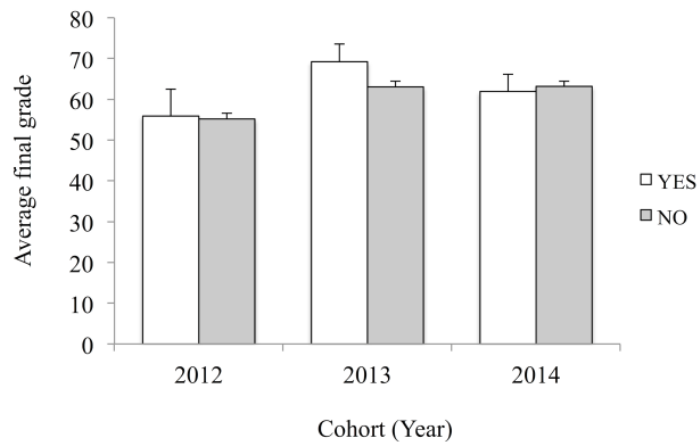

D.

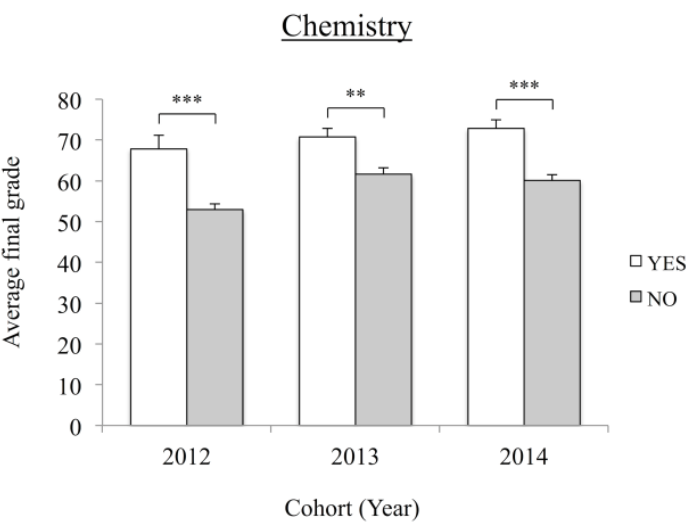

F.

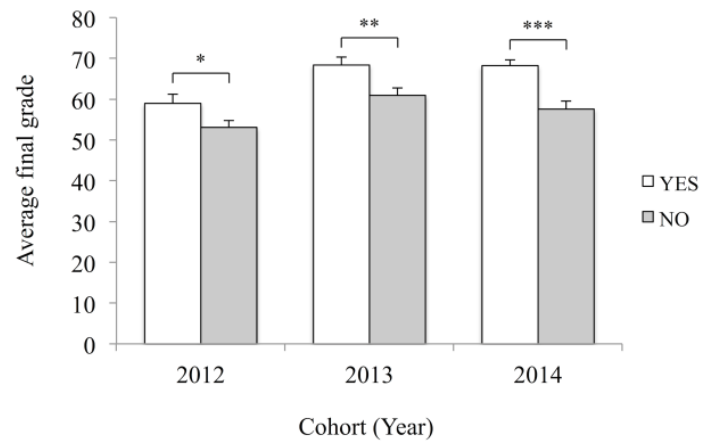

Figure 4. A student's previous study can predict academic performance in first year health science. Previous study in (A) human biology, (B) biology, (C) physics, (D) chemistry, (E) physical education studies and (F) advanced mathematics can predict academic performance in BMS100 $(* p<.05 ; * * p<.01 ; * * * p<.001)$. 
A.

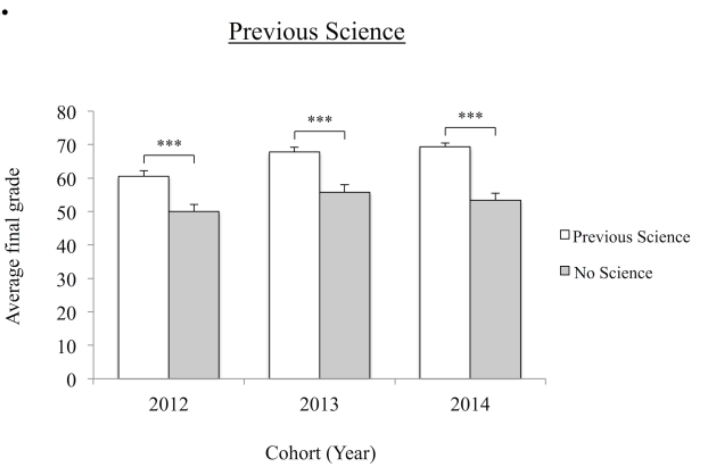

B.

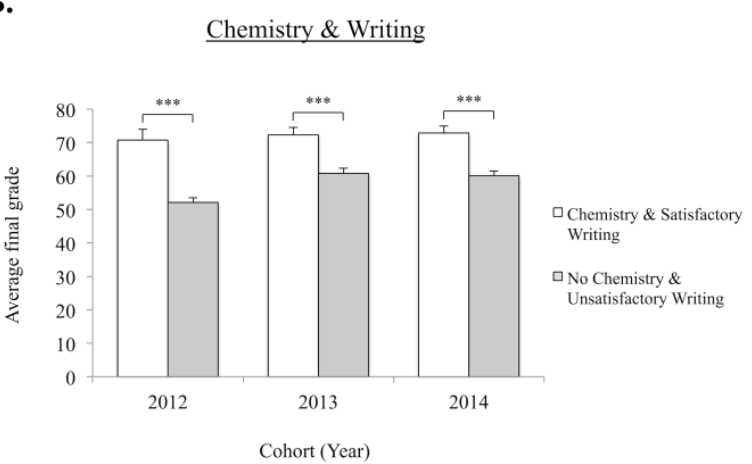

Figure 5. Combining multiple variables is associated with significantly higher academic performance in first year anatomy and physiology. (A) Previous study of science (human biology, chemistry or physics) strongly predicts academic performance in BMS100 $(* * * p<.001)$. (B) A combination of previous chemistry study and competency in writing improves academic performance in BMS100 $(* * * p<.001)$.

\subsection{Predictors of Academic Performance Using a GLM}

To clarify these results further, a GLM examined predictors of academic performance (BMS100 score). All potential academic predictors were incorporated into the GLM, and were sequentially removed until all remaining variables showed statistical significance. SES, mathematics and reading were found not to be significant predictors of BMS100 performance. The final model derived is reported in Table 3 and indicates that gender, course program, previous human biology, physics, chemistry, writing assessment and cohort year are together important predictors of academic performance. Specifically, student gender was a significant determinant of academic success, with female students scoring 4.69 points higher than males $(p<.001)$. Student course was an important predictor; with HPE degree students scoring 5.68 points lower than BMS degree students $(p=.007)$. Successful completion of the writing assessment in first semester increased student performance scores by $4.01(p=.019)$. Previous study of human biology, chemistry and physics was also shown to improve performance scores by $6.41(p<.001), 7.60(p$ $<.001)$ and $6.18(p=.007)$ points respectively. Within the model, these improvements are additive, and therefore a female student who had completed ATAR level human biology, physics and chemistry at secondary school and passed their writing assessment would have an increased performance score of 28.88 points. Cohort year indicated that 2012 was significantly different to other years, with this year's students performing worse $(p=.003)$.

Table 3. Final Model Parameter Estimates: Predictors of academic performance

\begin{tabular}{ccccc}
\hline & Variable & $\boldsymbol{\beta}$ coefficient & Std. Error & Significance \\
\hline Gender & Male & -4.686 & 1.319 & $<.001$ \\
Ceurse & Female & $0^{*}$ & & \\
& HPE & -5.862 & 2.175 & $\mathbf{. 0 0 7}$ \\
& BESS & -0.241 & 1.9462 & .901 \\
Previous human biology & BMS & $0^{*}$ & & \\
& No & -6.414 & 1.370 & $<.001$ \\
Previous physics & Yes & $0^{*}$ & & \\
Previous chemistry & No & -6.175 & 2.291 & $\mathbf{. 0 0 7}$ \\
Yes & No & -7.603 & 2.033 & $<.001$ \\
Writing assessment & Yes & $0^{*}$ & & $\mathbf{. 0 1 9}$ \\
& Insufficient & -4.010 & 1.712 & $\mathbf{. 0 0 3}$ \\
& Sufficient & $0^{*}$ & & $\mathbf{4 0}$ \\
& 2012 & -4.881 & 1.631 & 1.612 \\
\hline
\end{tabular}

* Comparison category set to zero 


\section{Discussion}

In this study we attempted to extract components of academic success or otherwise of health science students through their performance in a core first year anatomy and physiology unit, BMS100. Percentage score in this unit was highly concurrent with GPA at the completion of first year, affirming it as a suitable proxy for overall first year performance in health sciences.

While this is a novel finding for health science students, previous studies have identified a similar relationship in medical cohorts (Sitticharoon, Srisuma, Kanavitoon, \& Summachiwakij, 2014). Anatomy and physiology are integral components of a health science degree, indeed many anatomists believe that mastering the somewhat rote learning style of anatomy can aid students across multiple fields of study (Pandey \& Zimitat, 2007). The results from this study support this notion, as high scores in BMS100 coincide with, or even translate to, an impressive overall GPA.

If the grade obtained in first year anatomy and physiology was a predictor for academic success, what variables predicted these grades? Our results indicate that mode of entrance, degree program, and gender are significant factors in our cohorts. Final BMS100 grade for school leavers versus mature age students were significantly different in years 2013 and 2014, but when considered with other factors as predictors of performance, the mode of university entry did not seem to play an important role. University entrance scores themselves correlate to academic performance in science degrees, and Australian undergraduate medical degrees (McKenzie \& Schweitzer, 2001; Puddey \& Mercer, 2014). In our findings, degree program was an important variable, with the BMS cohorts significantly outperforming HPE cohorts by 13-14\% each year. While no ATAR or University entrance difference exists, many in the BMS cohort strive towards graduate entry medicine, possibly reflecting in their attitude towards study. Females consistently averaged higher grades over all three cohorts in BMS100, than males. As a significant variable in predicting academic success in BMS100, females would be expected to continue to perform better across the entirety of their health science degree. Given prior educational attainment is the most important predictor of academic success, and girls consistently perform better in secondary school (Duckworth \& Seligman, 2005; Fischer et al., 2013), it seems this is an advantage carried to higher education (McKenzie \& Schweitzer, 2001). The effect size of socioeconomic status (SES) varies in reports, but it was recently shown that SES does not influence academic performance at an Australian university ( $\mathrm{Li} \&$ Dockery, 2014). However, the demographic of the school can influence student performance, with equivalent students from less prestigious schools performing better than those from more prestigious schools in graduate medicine (Puddey \& Mercer, 2014) and general university (Li \& Dockery, 2014). Our data supports previous findings, with no statistical significance observed between students' SES, although the effect of secondary school demographic is of interest to further research.

The problem surrounding the decline in writing standards in health science students has previously been observed (McNaught \& Hoyne, 2012). Students who lack competency in writing were more likely to struggle with academic workloads at university (Lau, 2003). Previous work has identified a weak correlation between performance in a research and writing unit and BMS100 (McNaught \& Hoyne, 2012), presumably due to the distinct material differences between units. In this study we observed that writing competency, as determined by the PELA, was associated with higher academic performance in first year anatomy and physiology. However, this relationship was not observed with reading scores. It is unclear how writing proficiency translates to improved grades in BMS100, particularly as this unit requires minimal structured writing assessments. However, general literacy scores naturally relate to university entrance scores (Newell, 2012), suggesting the two variables are both important, despite an unclear connection.

Subjects studied in secondary school have previously shown to be associated with success in health science units at another Australian university (Green, Brown, \& Ward, 2009). In our study, significant increases in the average BMS100 grade were observed in all three cohorts when students studied mathematics at a year 12 level. However, when analysed in a GLM, mathematics was not found to be a significant predictor of performance, suggesting that higher-level mathematics may be coincidentally chosen alongside other ATAR science subjects, or is an indicator of higher-level thinking. In contrast, physics and chemistry were associated with higher performance scores and were a significant predictor of performance using the GLM. While a previous background in physics or chemistry would not be intuitive in an anatomy and physiology unit, both predictors combined increase BMS100 grade by approximately 13\%. This data supports a similar finding at La Trobe University, where high school chemistry and physics were seen to be associated with higher academic performance in several anatomy and physiology units (Green et al., 2009). The number of students entering university with higher level or intermediate mathematics, chemistry and physics is declining in Australia (Barrington, 2006; Rubinstein, 2009), which establishes an ongoing need for supporting this body of students as a collective. 
Past study of biological sciences and physical education (PE) were not shown to enhance academic performance. This is a surprising finding for PE studies, as many health science students commonly have this background, and this content is a precursor for several anatomical concepts. In contrast, human biology study in high school was a significant factor in all cohorts. Human biology appears to be a common intuitive predictor for a health science degree although the teaching delivery of BMS100 may be disparate and the theory more involved. Nevertheless, student background in human biology is purportedly of help with study techniques, familiarity with terminology, and understanding anatomical concepts (Sitticharoon et al., 2014). It is well recognised in the teaching literature that previous exposure to concepts, even an awareness of the degree of depth within topics, enhances student aptitude for difficult content. Why then, does this not apply to past PE study? While both PE and human biology contain foundation concepts, students entering University with secondary human biology may be better equipped to approach familiar topics, and less bewildered by the breadth of material covered in one semester of anatomy and physiology.

\section{Conclusions}

When comparing the strength of each predictor, the GLM determined science subjects, specifically Human Biology, Physics and Chemistry, as the most significant predictors of academic success, where gender, course chosen, and writing proficiency were also important. The study of advanced science units, including anatomy, is becoming more difficult for continually larger groups of students with inadequate secondary school backgrounds (Green et al., 2009). It is worth noting that these characteristics are merely predictors, as a male student with lower writing proficiency and no science background is not predestined to perform poorly. Rather, unmasking these predictors of performance enables university faculties to understand what makes the university transition difficult. While universally available, support services can become increasingly customized to these student vulnerabilities, or marketed to these individuals. Existing approaches to improve writing proficiency and assist students without a previous science background have been an option prior to the commencement, and during, their undergraduate degrees. Despite offering such programs, improving attendance rates has remained challenging (McNaught \& Hoyne, 2012). The authors have contemplated such a predicament, and raise the possibility of compulsory short courses for student populations predicted to be at most risk of academic failure.

This study has validated first year anatomy and physiology as an indicator of performance in health science degrees. Moreover, demographic and secondary education predictors of academic performance have been identified, warranting further study and consideration in additional disciplines. We anticipate that tailoring or targeting services to students most likely to falter will improve student's transition to university, retention and ultimately graduation.

\section{References}

Australian Bureau of Statistics [ABS] (2013). Census of Population and Housing: Socio-Economic Indexes for Areas (SEIFA), Australia, 2011. Census of Population and Housing: Socio-Economic Indexes for Areas (SEIFA), Australia, 2011 , from http://www.abs.gov.au/ausstats/abs@.nsf/DetailsPage/2033.0.55.0012011?OpenDocument

Duckworth, A. L., \& Seligman, M. E. (2005). Self-discipline outdoes IQ in predicting academic performance of adolescents. Psychol Sci, 16(12), 939-944. http://dx.doi.org/10.1111/j.1467-9280.2005.01641.x

Fischer, F., Schult, J., \& Hell, B. (2013). Sex differences in secondary school success: Why female students perform better. European Journal of Psychology of Education, 28(2), 529-543. http://dx.doi.org/10.1007/s10212-012-0127-4

Green, R., Brown, E., \& Ward, A. (2009). Secondary school science predictors of academic performance in university bioscience subjects. Anat Sci Educ, 2(3), 113-118. http://dx.doi.org/10.1002/ase.82

Harackiewicz, J. M., Barron, K. E., Tauer, J. M., \& Elliot, A. J. (2002). Predicting success in college: A longitudinal study of achievement goals and ability measures as predictors of interest and performance from freshman year through graduation. Journal of Educational Psychology, 94(3), 562-575. http://dx.doi.org/10.1037/0022-0663.94.3.562

Hassan, G. (2008). Attitudes toward science among Australian tertiary and secondary school students. Research in Science \& Technological Education, 26(2), 129-147. http://dx.doi.org/10.1080/02635140802034762

Hoffman, J., \& Lowitzki, K. (2005). Predicting college success with high school grades and test scores: limitations for minority students. The Review of Higher Education, 8(4). http://dx.doi.org/10.1353/rhe.2005.0042

Lau, L. K. (2003). Institutional factors affecting student retention. Education, 124(1), 126-136. 
Li, I., \& Dockery, M. (2014). Socio-economic status of schools and university academic performance: implications for Australia's higher education expansion. National Centre for Student Equity in Higher Education, Perth, W.A.: Curtin University.

Macey, D. J., Jordan, S., Jackson, G., \& Money, L. (2006). A review of alternative entry strategies into Australian universities. Perth, W.A.: Murdoch University.

McKenzie, K., \& Schweitzer, R. (2001). Who succeeds at university? Factors predicting academic performance in first year Australian university students. Higher Education Research \& Development, 20(1), 21-33. http://dx.doi.org/10.1080/07924360120043621

McNaught, K., \& Hoyne, G. (2012). Predicting a student's success in Health Sciences based on their academic writing skills. . Paper presented at the International First Year in Higher Education Conference, Brisbane.

Naderi, H., Abdullah, R., Aizan, H. T., Sharir, J., \& Kumar, V. (2009). Creativity, age and gender as predictors of academic achievement among undergraduate students. Journal of American Science, 5(5), 101-112.

Newell, F. (2012). Discipline-linked further education: Springboard to tertiary completion. International Journal of Training Research, 10(2), 105-117. http://dx.doi.org/10.5172/ijtr.2012.10.2.105

Pandey, P., \& Zimitat, C. (2007). Medical students' learning of anatomy: Memorisation, understanding and visualisation. Med Educ, 41(1), 7-14. http://dx.doi.org/10.1111/j.1365-2929.2006.02643.x

Puddey, I. B., \& Mercer, A. (2014). Predicting academic outcomes in an Australian graduate entry medical programme. BMC Med Educ, 14, 31. http://dx.doi.org/10.1186/1472-6920-14-31

Richardson, M., Abraham, C., \& Bond, R. (2012). Psychological correlates of university students' academic performance: A systematic review and meta-analysis. Psychological Bulletin, 138(2), 353-387. http://dx.doi.org/10.1037/a0026838

Shah, C., \& Burke, G. (1996). Student Flows in Australian Higher Education. Canberra: Australian Government Publishing Service.

Sheard, M. (2009). Hardiness commitment, gender, and age differentiate university academic performance. British Journal of Educational Psychology, 79(1), 189-204. http://dx.doi.org/10.1348/000709908X304406

Sitticharoon, C., Srisuma, S., Kanavitoon, S., \& Summachiwakij, S. (2014). Exploratory study of factors related to educational scores of first preclinical year medical students. Adv Physiol Educ, 38(1), 25-33. http://dx.doi.org/10.1152/advan.00162.2012

Stinebrickner, R., \& Stinebrickner, T. (2003). Working during school and academic performance. Journal of Labor Economics, 21(2), 473-491. http://dx.doi.org/10.1086/345565 